\title{
Metabolismo energético, proteico e mineral de ovelhas Santa Inês hígidas e com mastite subclínica ${ }^{1}$
}

\author{
José S.C. da Silva ${ }^{2 *}$, Eduardo L. de S. Guaraná ${ }^{3}$, Vânia F. Lemos² , Pierre C. Soares, \\ José A.B. Afonso ${ }^{5}$ e Carla L. de Mendonça ${ }^{5}$
}

\begin{abstract}
Silva J.S.C., Guaraná E.L.S., Lemos V.F., Soares P.C., Afonso J.A.B. \& Mendonça C.L. 2013. [Energy, protein and mineral metabolism in Santa Inês ewes, both healthy and with subclinical mastitis.] Metabolismo energético, proteico e mineral de ovelhas Santa Inês hígidas e com mastite subclínica. Pesquisa Veterinária Brasileira 33(9):1087-1096. Clínica de Bovinos, Campus Garanhuns, Universidade Federal Rural de Pernambuco, Av. Bom Pastor s/n, Boa Vista, Garanhuns, PE 55292-270, Brazil. E-mail: carlalopes.mendonca@gmail.com

The study aimed to evaluate the energy, protein and mineral metabolism in Santa Inês ewes, healthy and with subclinical mastitis, followed up during late gestation and lactation periods. Ewes subjected to the same semi-intensive nursing system were followed up. The animals were evaluated according to the following stages: 10 days before parturition (dbp) and 15 days postpartum (dpp), $30 \mathrm{dpp}, 60 \mathrm{dpp}$, and $90 \mathrm{dpp}$. Blood metabolites were evaluated starting from the stage previous to parturition and whey metabolites were evaluated in the subsequent stages. A screening of the ewes followed up in this study (12 healthy and 18 with subclinical mastitis) was performed after a clinical and bacteriological examination. During lactation, maintaining the same screening criteria, 11 healthy and 20 infected mammary glands were selected; the milk for whey extraction was collected from these glands. Energy profile metabolites (non-esterified fatty acids [NEFAs], ß-hydroxybutyrate [BHB], fructosamine, cholesterol and triglycerides), protein profile (total protein, albumin, urea and creatinine) and mineral profile (iron, copper, zinc, magnesium, total calcium, ionized calcium, sodium, and potassium) were measured in the blood serum. Calcium, sodium and potassium ions, as well as NEFAs and BHB were measured in the whey. Blood biochemistry revealed an influence $(\mathrm{P}<0.05)$ of the peripartum and lactation periods on the blood concentrations of NEFAs, BHB, cholesterol, albumin, urea, ionized calcium. An analysis of the whey also revealed an influence on the potassium ion. Ewes with subclinical mastitis showed higher $(\mathrm{P}<0.05)$ blood levels of cholesterol, albumin and copper; higher sodium ion concentrations and NEFAs, and lower potassium ion in whey. Good physical score of ewes observed during this study, combined with the biochemical findings, allowed us to conclude that there was a larger energy requirement in the first month of lactation; however, this requirement was not enough to trigger any metabolic disorder or the emergence of ketonemia, and these discrete changes were more apparent in ewes with subclinical mastitis.
\end{abstract}

INDEX TERMS: Metabolic profile, sheep, pregnant ewes, lactating, blood serum, infection of the mammary gland, mastitis, whey.

\footnotetext{
${ }^{1}$ Recebido em 13 de abril de 2013.

Aceito para publicação em 3 de agosto de 2013.

${ }^{2}$ Programa de Pós-Graduação em Sanidade e Reprodução de Ruminantes, Universidade Federal Rural de Pernambuco (UFRPE), Av. Bom Pastor s/n, Cx. Postal 152, Boa Vista, Garanhuns, PE 55292-270, Brasil. *Autor para correspondência: carlalopes.mendonca@gmail.com

${ }^{3}$ Programa de Pós-Graduação em Ciência Veterinária, UFRPE, Av. Dom Manoel de Medeiros s/n, Dois Irmãos, Recife, PE 51171-900, Brasil.

${ }^{4}$ Departamento de Medicina Veterinária, UFRPE, Av. Dom Manoel de Medeiros s/n, Dois Irmãos, Recife, PE.

${ }^{5}$ Clínica de Bovinos, Campus Garanhuns, UFRPE, Av. Bom Pastor s/n, Cx. Postal 152, Boa Vista, Garanhuns, PE.
}

RESUMO.- Este estudo teve por objetivo avaliar o metabolismo energético, proteico e mineral de ovelhas Santa Inês hígidas e com mastite subclínica acompanhadas durante o final da gestação e na lactação. Foram acompanhadas ovelhas submetidas ao mesmo sistema de criação semi-intensivo. Os animais foram avaliados conforme os momentos a seguir: 10 dias que precedeu o parto (dap) e 15 dias pós parto (dpp), $30 \mathrm{dpp}, 60 \mathrm{dpp}$ e $90 \mathrm{dpp}$. Os metabólitos sanguíneos foram avaliados a partir do momento que antecedeu ao parto e os metabólitos no soro lácteo nos momentos 
subsequentes. Após exame clínico e bacteriológico foi realizada a triagem das ovelhas acompanhadas neste estudo, sendo 12 hígidas e 18 com mastite subclínica. Durante a lactação, mantendo os mesmos critérios de triagem, foram selecionadas 11 glândulas mamárias sadias e 20 infectadas, das quais foi colhido o leite para obtenção do soro lácteo. Foram mensurados no soro sanguíneo os metabólitos do perfil energético (ácidos graxos não esterificados (AGNEs), ß-hidroxibutirato (BHB), frutosamina, colesterol e triglicérides), do perfil proteico (proteína total, albumina, uréia e creatinina) e do perfil mineral (ferro, cobre, zinco, magnésio, cálcio total, cálcio ionizado, sódio e potássio). No soro lácteo foram mensurados os íons cálcio, sódio e potássio, bem como os AGNEs e o BHB. A bioquímica sanguínea revelou haver influência $(\mathrm{P}<0,05)$ do período do periparto e da lactação sobre as concentrações sanguíneas dos AGNEs, BHB, colesterol, albumina, uréia, cálcio ionizado e no soro lácteo sobre o íon potássio. As ovelhas portadoras de mastite subclínica apresentaram valores sanguíneos superiores $(\mathrm{P}<0,05)$ de colesterol, albumina e cobre e no soro lácteo teores superiores do íon sódio e dos AGNEs e inferiores do íon potássio. 0 bom escore corporal das ovelhas observado durante o estudo aliado aos achados bioquímicos permitiu concluir ter ocorrido maior requerimento energético no primeiro mês da lactação, porém não o suficiente para desencadear qualquer transtorno metabólico e o aparecimento de um quadro de cetonemia, sendo estas discretas alterações mais expressivas nas ovelhas com mastite subclínica.

TERMOS DE INDEXAÇÃO: Perfil metabólico, ovinos, ovelhas gestantes, lactação, soro sanguíneo, infecção da glândula mamária, mastite, soro lácteo.

\section{INTRODUÇÃO}

A necessidade de melhoria na produção de ovinos, tanto para carne como leite, com intuito de atender a demanda retraída, tem estimulado o melhoramento genético nos rebanhos, mas a intensificação do sistema de manejo alimentar, com práticas que desafiam o limiar do metabolismo animal, tem provocado a crescente ocorrência de distúrbios sanitários e metabólicos, que acarretam sérias perdas ao produtor (Afonso 2005, Smith \& Sherman 2009).

0 período entre o final da gestação e o início da lactação, também conhecido como período de transição, tem sido considerado o estágio de maior interesse do ciclo produtivo. Neste período ocorrem diversas alterações anatômicas, fisiológicas, hormonais e metabólicas, em que a fêmea se prepara para o parto e o início da lactação, podendo resultar no aparecimento de distúrbios sanitários no pós-parto, que comprometem a produtividade (Brito et al. 2006, Piccione et al. 2009, Cardoso et al. 2011).

As alterações físicas e metabólicas observadas no periparto podem reduzir os mecanismos de defesa inata e adquirida da glândula mamária, contribuindo para o aumento da incidência da mastite durante a lactação (Mallard et al. 1998, Moyes et al. 2009).

Em ovelhas, os distúrbios do metabolismo e a mastite acarretam perdas econômicas significativas ao produtor, pois podem comprometer a produção de leite, reduzir o ganho de peso do borrego e até mesmo promover a morte precoce; tais prejuízos podem ser minimizados a partir do conhecimento das possíveis variações metabólicas sistêmicas que são desencadeadas na fêmea no periparto e durante a lactação (Ribeiro et al. 2004, Cardoso et al. 2011), constituindo importante ferramenta clínico-laboratorial na sinalização de distúrbios metabólicos orgânicos.

Diante do exposto e da escassa literatura, no que diz respeito ao acompanhamento de ovelhas sob condições de campo, e não apenas avaliações pontuais, este estudo teve como objetivo avaliar as alterações relacionadas ao metabolismo energético, proteico e mineral na fase final da gestação, bem como durante a lactação de ovelhas hígidas e acometidas com mastite subclínica.

\section{MATERIAL E MÉTODOS}

Acompanhou-se o período final da gestação e a lactação de um rebanho de ovelhas da raça Santa Inês criadas em sistema semi-intensivo, submetidas ao mesmo manejo higiênico-sanitário e nutricional. A dieta dos animais era constituída de pastagem, ração concentrada para ovelhas, sal mineral e água ad libitum.

Os momentos de avaliação compreenderam os 10 dias que precederam ao parto (dap), 15 dias pós-parto (dpp), $30 \mathrm{dpp}, 60$ dpp e 90 dpp (período de desmame na região) para as variáveis determinadas no sangue e nos respectivos momentos pós-parto para as variáveis determinadas no soro lácteo.

0 acompanhamento clínico (Diffay et al. 2005), paralelamente ao resultado simultâneo negativo ou positivo, do California Mastitis Test (CMT) (Schalm et al. 1971), do exame bacteriológico ( $\mathrm{Na}$ tional Mastitis Council 1990, Quinn et al. 1994) e do exame clínico da glândula mamária, permitiu a triagem das ovelhas acompanhadas neste estudo ao longo dos momentos de avaliação, totalizando 12 ovelhas hígidas e 18 portadoras de mastite subclínica, das quais foram colhidos o material para avaliação dos metabólitos sanguíneos. Durante a fase da lactação, mantendo os mesmos critérios de triagem, foram selecionadas 11 glândulas mamárias sadias e 20 infectadas, das quais foi colhido o leite para obtenção do soro lácteo.

Para avaliação do perfil metabólico (perfil energético, proteíco e mineral) foram colhidos $10 \mathrm{~mL}$ de sangue mediante punção da veia jugular em tubos esterelizados a vácuo ${ }^{6}$ sem anticoagulante para obtenção do soro. As amostras foram centrifugadas a $1600 \mathrm{~g}$ por cinco minutos ${ }^{7}$. Os soros, livre de hemólise, foram separados por aspiração e estocados em tubos tipo eppendorf, sendo mantidos em freezer à $-80^{\circ} \mathrm{C} .{ }^{8}$

Para avaliação do perfil metabólico no soro lácteo, as amostras de leite foram colhidas após antissepsia do óstio do teto. 0 soro lácteo foi obtido por coagulação do leite após adição de solução de renina (coalho Estrela ${ }^{\circledR)}$ e as amostras centrifugadas a $21.000 \mathrm{~g}$ por 10 minutos em centrífuga refrigerada $a^{9}$; posteriormente a fração intermediária, resultante da solução trifásica, correspondente ao soro lácteo, foi fracionada em tubos tipo eppendorf (Lemos 2011) e mantidas em ultrafreezer ${ }^{8}$ a $-80^{\circ} \mathrm{C}$ para posterior determinação dos eletrólitos, do BHB e dos AGNEs.

No soro sanguíneo foram mensurados os metabólitos proteína total pelo método do biureto (Labtest Diagnóstica S.A.); albumina

\footnotetext{
${ }^{6}$ Vacutainer, Bencton Dickinson, Franklin Lakes, NJ, USA.

${ }^{7}$ Centrifugador Excelsa 2, Fanem Ltda.

${ }^{8}$ NUAIRE Ultralow Freezer.

${ }^{9}$ Mikro 200R Hettich-Zentrifugen.
} 
pelo método do verde de bromocresol (Labtest Diagnóstica S.A.); uréia pelo método enzimático (Uréia CE Labtest Diagnóstica S.A.); creatinina (Labtest Diagnóstica S.A); $\beta$-hidroxibutirato (BHB/ RANBUT Randox Laboratories Ltd) pelo método cinético enzimático, ácidos graxos não esterificados, pelo método enzimático (NEFA Randox Laboratories Ltd), colesterol (Colesterol liquiform Labtest Diagnóstica S.A.), triglicérides (Triglicérides liquiform Labtest Diagnóstica S.A.), frutosamina (Labtest Diagnóstica S.A.), cálcio total (Cálcio liquiform Labtest Diagnóstica S.A.) e magnésio (Magnesio Labtest Diagnóstica S.A.). As leituras foram efetuadas a $37^{\circ} \mathrm{C}$ em analisador bioquímico semi-automático ${ }^{10}$. 0 ferro, o cobre e o zinco foram determinados seguindo as recomendações de Solamain et al. (2001), homogeneizando $4 \mathrm{~mL}$ da água acidificada em $1 \mathrm{~mL}$ do soro teste, com posterior centrifugação a $1600 \mathrm{~g}$ por 10 minutos. A determinação dos teores destes microelementos foi realizada por espectrometria de emissão ótica ${ }^{11}$.

Os níveis dos íons cálcio, sódio e potássio no soro sanguíneo e no soro lácteo foram determinados em analisador de eletróli$\operatorname{tos}^{12}$. No soro lácteo foi também mensurado o $\beta$-hidroxibutirato (BHB/RANBUT Randox Laboratories Ltd) e os ácidos graxos não esterificados (AGNEs), pelo método enzimático (NEFA Randox Laboratories Ltd).

Análise Estatística: Os dados foram submetidos à análise de variância (Teste F), nos casos de significância no teste F, as médias foram comparadas pela diferença mínima significativa (d.m.s.) do teste de Student-Newman-Keuls. Foi realizada análise de regressão das variáveis em função dos momentos de observação. Os dados foram analisados por meio do programa computacional Statistical Analysis System (SAS 2009). Para todas as análises estatísticas realizadas foi adotado o nível de significância (p) de $5 \%$. As análises foram realizadas de acordo com o modelo estatístico: $Y i j=\mu+\mathrm{Ti}$ + Dj + TDij Gij, em que: Yij = observação em relação aos grupos e aos momentos sobre a repetição ij; $\mu=$ constante relacionada com todas as observações; $\mathrm{Ti}$ = efeito de grupo na i repetição; $\mathrm{Dj}$ = efeito de momento sobre a j repetição; TDij = interação de grupos $\mathrm{x}$ momentos e $€ \mathrm{ij}$ = erro em relação a todas as observações (Sampaio 2007).

O trabalho obteve parecer favorável da Comissão de Ética no Uso de Animais (CEUA), da Universidade Federal Rural de Pernambuco com a licença n. 017/2010 (6029/2010 D08) CEPE/ UFRPE de acordo com as normas do COBEA e National Institute of Health Guide for Care and Use of Laboratory Animals.

\section{RESULTADOS E DISCUSSÃO}

As ovelhas hígidas e com mastite subclínica apresentaram-se clinicamente saudáveis e com boa condição corpórea durante o período de acompanhamento, com escore corporal variando de 2,5 a 3,5 em todos os momentos de observação, sendo os menores valores da escala observados próximo ao parto e no início da lactação. Resultados semelhantes foram descritos por Caldeira et al. (2007), que num experimento verificou escore corporal 3 em ovelhas gestantes, que apresentaram perfil bioquímico equilibrado do status metabólico.

\section{Soro sanguíneo}

As fontes de variação, o valor de F da análise de variância e o nível de $P$ das variáveis referentes ao perfil energético, proteico e mineral podem ser visualizados no Quadro 1.

\footnotetext{
${ }^{10}$ Labquest, Labtest Diagnóstica S.A., Lagoa Santa, MG.

${ }^{11}$ ICP-OES/Optima 7000, Perkin Elmer.

${ }^{12}$ Mod.9180, Cobas, Roche Diagnostics.
}

Quadro1. Nível de significância (Pr>F) dos fatores de variação (grupos, momentos e interações) da análise de variância dos metabólitos referentes ao perfil energético, proteico e mineral do soro sanguíneo de ovelhas Santa Inês hígidas e com mastite subclínica acompanhadas no final da gestação e durante a lactação

\begin{tabular}{|c|c|c|c|}
\hline \multirow[t]{3}{*}{ Metabólitos } & \multicolumn{3}{|c|}{ Fatores de variação $(\mathrm{Pr}>\mathrm{F})$} \\
\hline & Grupos & Momentos & $\mathrm{G} \times \mathrm{M}$ \\
\hline & \multicolumn{3}{|c|}{ Soro sanguíneo } \\
\hline AGNEsa (mmol/L) & 0,7451 & 0,0008 & 0,4912 \\
\hline ß-hidroxibutirato $(\mathrm{mmol} / \mathrm{L})$ & 0,9238 & 0,0021 & 0,5520 \\
\hline Frutosamina $(\mu \mathrm{mol} / \mathrm{L})$ & 0,8039 & 0,5767 & 0,7657 \\
\hline Colesterol (mg/dL) & 0,0070 & 0,0467 & 0,1017 \\
\hline Triglicérides (mg/dL) & 0,4032 & 0,0965 & 0,2513 \\
\hline Proteina Total (g/dL) & 0,9555 & 0,3642 & 0,9650 \\
\hline Albumina $(\mathrm{g} / \mathrm{dL})$ & 0,0500 & 0,0015 & 0,4374 \\
\hline Uréia (mg/dL) & 0,0757 & 0,0498 & 0,3818 \\
\hline Creatinina (mg/dL) & 0,2016 & 0,2950 & 0,8659 \\
\hline Cálcio Total (mmol/L) & 0,8305 & 0,3679 & 0,4016 \\
\hline Cálcio ionizado (mmol/L) & 0,8879 & 0,0009 & 0,2977 \\
\hline Magnésio (mg/dL) & 0,2759 & 0,1180 & 0,5737 \\
\hline Sódio $(\mathrm{mmol} / \mathrm{L})$ & 0,5035 & 0,4404 & 0,9930 \\
\hline Potássio (mmol/L) & 0,3818 & 0,9264 & 0,8298 \\
\hline Ferro (mg/L) & 0,2079 & 0,4727 & 0,8189 \\
\hline Zinco (mg/L) & 0,2411 & 0,8871 & 0,9717 \\
\hline Cobre $(\mathrm{mg} / \mathrm{L})$ & 0,0500 & 0,8625 & 0,7102 \\
\hline
\end{tabular}

${ }^{\mathrm{a}}$ AGNEs = Ácidos graxos não esterificados.

\section{Perfil energético}

$\mathrm{Na}$ avaliação dos ácidos graxos não esterificados (AGNEs), não foi verificada diferença entre os grupos, no entanto houve variação significativa entre os momentos (Quadro 1). Foi observado aumento gradativo nos valores médios de AGNEs nas primeiras semanas da lactação, com a maior média obtida aos $30 \mathrm{dpp}(0,81 \mathrm{mmol} / \mathrm{L})$, coincidindo com o período do pico da lactação e posterior decréscimo, com a menor média obtida aos 90 dias (0,35 mmol/L) (Quadro 2). Apesar das diferenças estatísticas observadas entre os momentos de avaliação, os valores de AGNEs obtidos encontram-se dentro da normalidade para a espécie, valendo salientar que a média observada aos 30 dias encontra-se no limite superior de normalidade (Contreras et al. 2000), sugerindo haver lipomobilização de baixa magnitude. Estes achados chamam atenção particularmente no grupo das ovelhas com mastite subclínica, no qual verificou-se efeito quadrático $(\mathrm{P}<0,01)$ ao longo dos momentos de observação, evidenciando maior lipomobilização neste grupo, que apresentou valores médios de $0,82 \mathrm{mmol} / \mathrm{L}$ nos 30 dias da lactação.

Este comportamento do AGNEs foi relatado por González \& Silva (2006), que atribuiram concentrações mais elevadas desta variável, próximo ao parto e após o mesmo, ao menor consumo de alimento e a maior produção de leite. Desta forma, ficou evidente maior requerimento energético no início e no pico da lactação, porém não o suficiente para desencadear qualquer transtorno metabólico (Contreras et al. 2000). Santos et al. (2012), trabalhando com ovelhas desta mesma raça suplementadas com propilenoglicol relataram valores inferiores deste metabólito no anteparto e até os 30 dias de lactação. Resultados semelhantes foram também verificados por Rios et al. (2006) trabalhando com 
Quadro 2. Valores médios e desvio padrão $(\mathrm{x} \pm \mathrm{s})$ das variáveis do perfil energético no soro sanguíneo de ovelhas Santa Inês hígidas e com mastite subclínica acompanhadas no final da gestação e durante a lactação

\begin{tabular}{|c|c|c|c|c|c|c|c|}
\hline \multirow[t]{2}{*}{ Perfil energético } & \multirow[t]{2}{*}{ Ovelhas } & \multicolumn{4}{|c|}{ Momentos de avaliação } & & \multirow[t]{2}{*}{$\mathrm{MG}^{\mathrm{e}}$} \\
\hline & & 10dap ${ }^{b}$ & $15 \mathrm{dpp}^{\mathrm{c}}$ & 30dpp & 60dpp & 90dpp & \\
\hline $\begin{array}{l}\text { AGNEsa } \\
(\mathrm{mmol} / \mathrm{L})\end{array}$ & $\begin{array}{c}\text { Hígidas } \\
\text { Mast.Subd. } \\
\text { MG }\end{array}$ & $\begin{array}{c}0,77 \pm 0,49 \\
0,49 \pm 0,44 \\
0,63^{\text {abc }}\end{array}$ & $\begin{array}{c}0,69 \pm 0,41 \\
0,72 \pm 0,50 \\
0,71^{\text {ab }}\end{array}$ & $\begin{array}{c}0,80 \pm 0,61 \\
0,82 \pm 0,55 \\
0,81^{\text {a }}\end{array}$ & $\begin{array}{c}0,39 \pm 0,36 \\
0,48 \pm 0,30 \\
0,44^{\text {bc }}\end{array}$ & $\begin{array}{c}0,32 \pm 0,24 \\
0,39 \pm 0,22 \\
0,35^{c}\end{array}$ & $\begin{array}{l}0,59^{\mathrm{a}} \\
0,58^{\mathrm{a}}\end{array}$ \\
\hline $\begin{array}{l}\text { B-hidroxibutirato } \\
\text { (mmol/L) }\end{array}$ & $\begin{array}{l}\text { Hígidas } \\
\text { Mast.Sub. } \\
\text { MG }\end{array}$ & $\begin{array}{c}0,52 \pm 0,15 \\
0,48 \pm 0,14 \\
0,50^{\mathrm{a}}\end{array}$ & $\begin{array}{c}0,40 \pm 0,18 \\
0,40 \pm 0,11 \\
0,40^{\mathrm{b}}\end{array}$ & $\begin{array}{c}0,35 \pm 0,12 \\
0,40 \pm 0,10 \\
0,38^{b}\end{array}$ & $\begin{array}{c}0,42 \pm 0,11 \\
0,37 \pm 0,08 \\
0,39^{\mathrm{b}}\end{array}$ & $\begin{array}{c}0,36 \pm 0,08 \\
0,39 \pm 0,18 \\
0,38^{b}\end{array}$ & $\begin{array}{l}0,41^{\mathrm{a}} \\
0,41^{\mathrm{a}}\end{array}$ \\
\hline $\begin{array}{l}\text { Frutosamina } \\
(\mu \mathrm{mol} / \mathrm{L})\end{array}$ & $\begin{array}{l}\text { Hígidas } \\
\text { Mast.Sub. } \\
\text { MG }\end{array}$ & $\begin{array}{c}177,57 \pm 16,32 \\
171,14 \pm 20,12 \\
174,36^{a}\end{array}$ & $\begin{array}{c}177,83 \pm 20,76 \\
177,01 \pm 14,21 \\
177,42^{a}\end{array}$ & $\begin{array}{c}177,95 \pm 20,66 \\
172,62 \pm 22,36 \\
175,29^{a}\end{array}$ & $\begin{array}{c}169,35 \pm 19,97 \\
172,29 \pm 24,96 \\
170,82^{\mathrm{a}}\end{array}$ & $\begin{array}{c}163,54 \pm 20.93 \\
170,70 \pm 28,77 \\
167,12^{a}\end{array}$ & $\begin{array}{l}173,25^{\mathrm{a}} \\
172,75^{\mathrm{a}}\end{array}$ \\
\hline $\begin{array}{l}\text { Triglicérides } \\
\text { (mg/dL) }\end{array}$ & $\begin{array}{c}\text { Hígidas } \\
\text { Mast.Sub. } \\
\text { MG }\end{array}$ & $\begin{array}{c}16,10 \pm 4,89 \\
19,07 \pm 5,54 \\
17,58^{\mathrm{a}}\end{array}$ & $\begin{array}{c}18,97 \pm 6,02 \\
17,44 \pm 6,42 \\
18,20^{\mathrm{a}}\end{array}$ & $\begin{array}{c}22,46 \pm 9,65 \\
18,13 \pm 5,45 \\
20,29^{a}\end{array}$ & $\begin{array}{c}20,00 \pm 4,14 \\
21,28 \pm 12,74 \\
20,64^{\mathrm{a}}\end{array}$ & $\begin{array}{c}23,27 \pm 5,99 \\
19,75 \pm 8,14 \\
21,51^{\mathrm{a}}\end{array}$ & $\begin{array}{l}20,16^{\mathrm{a}} \\
19,14^{\mathrm{a}}\end{array}$ \\
\hline $\begin{array}{l}\text { Colesterol } \\
\text { (mg/dL) }\end{array}$ & $\begin{array}{l}\text { Hígidas } \\
\text { Mast.Sub. } \\
\text { MG }\end{array}$ & $\begin{array}{c}54,83 \pm 12,25 \\
52,18 \pm 14,07 \\
53,50^{a b}\end{array}$ & $\begin{array}{c}46,26 \pm 9,97 \\
52,10 \pm 9,14 \\
49,18 \mathrm{~b}\end{array}$ & $\begin{array}{c}53,19 \pm 9,31 \\
58,12 \pm 15,58 \\
55,65^{a b}\end{array}$ & $\begin{array}{c}52,25 \pm 7,68 \\
59,24 \pm 12,96 \\
55,75^{a b}\end{array}$ & $\begin{array}{c}48,37 \pm 9,17 \\
67,01 \pm 23,46 \\
57,69^{a}\end{array}$ & $\begin{array}{l}50,98 \mathrm{~b} \\
57,73^{\mathrm{a}}\end{array}$ \\
\hline
\end{tabular}

$\overline{{ }^{a} \text { AGNEs }=\text { Ácidos graxos não esterificados }},{ }^{\mathrm{b}}$ dap $=$ dias antes do parto, ${ }^{\mathrm{c}} \mathrm{dpp}=$ dias pós parto, ${ }^{\mathrm{d}}$ Mast. Sub. $=$ Mastite subclínica, ${ }^{\mathrm{e}} \mathrm{MG}=$ Média Geral.

cabras leiteiras, que observaram valores baixos de AGNEs no final da gestação e que se elevaram no primeiro terço da lactação, atribuindo ao déficit energético da ração aliado ao maior requerimento da cabra no período de elevada produção leiteira.

Não foi observada diferença significativa na concentração sanguínea de $\beta$-hidroxibutirato entre os grupos, contudo verificou-se efeito de momento (Quadro 1) com diminuição significativa dos valores médios desta variável, comparando-se o período que antecedeu ao parto, no qual foi obtida a maior média $(0,50 \mathrm{mmol} / \mathrm{L})$ e a fase da lactação (Quadro 2). A análise de regressão ao longo dos momentos de observação apresentou efeito do tipo linear negativo $(P<0,05)$ para ambos os grupos, caracterizando o decréscimo deste metabólito durante a lactação. Valores mais elevados de BHB ao final da gestação, acompanhado posteriormente por decréscimo na fase de lactação foi também observado por Oliveira et al. (2008) e Cardoso et al. (2010) em ovelhas Santa Inês, sugerindo a provável mobilização de nutrientes para atender as necessidades de energia das ovelhas que normalmente ocorrem no período que antecede o parto.

Diferentemente dos resultados deste estudo, Ribeiro et al. (2004) e Brito et al. (2006) verificaram valores superiores deste metabólito na lactação, quando comparado ao final da gestação, justificando este achado ao baixo teor de ingestão calórica e consequente consumo de reservas corporais no início da lactação, associados à diminuição da condição corporal também verificada nestes estudos. Os valores encontrados em todos os momentos de observação, inclusive no que precede ao parto encontram-se dentro da normalidade para a espécie ovina, ou seja, inferior a $0,6 \mathrm{mmol} / \mathrm{L}$, indicando não ter ocorrido um quadro de cetonemia (Contreras et al. 2000).

Com relação às concentrações de frutosamina não foram verificadas diferenças significativas entre os grupos e entre os momentos $(P>0,05)$. No entanto, foi observada uma discreta diminuição nas concentrações médias de frutosamina ao longo da lactação (Quadro 2). Valores médios inferiores aos obtidos neste estudo foram reportados por Soares et al. (2009) em ovelhas Dorper no anteparto e no pós-parto e por Filipovi'c et al. (2011), que verificaram valores médios de 157,0 $\mu \mathrm{mol} / \mathrm{L}$ no final da gestação e de 158,0 $\mu \mathrm{mol} / \mathrm{L}$ no período de lactação.

Pelo fato de ser a frutosamina uma cetoamina estável, formada por uma reação não enzimática da glicose com grupos aminas das proteínas, principalmente a albumina e sua concentração sanguínea controlada pelo balanço entre a síntese e eliminação destes compostos proteicos e com a glicose, a discreta diminuição observada nas concentrações da frutosamina durante a lactação, provavelmente resultou da redução da albumina que seguiu a mesma dinâmica neste estudo. Concentrações mais baixas de frutosamina no final da gestação e no pico da lactação, relacionando aos momentos de maior demanda de energia foram relatadas por Brito et al. (2006), ao estudarem o perfil metabólico em ovelhas leiteiras no sul do Brasil, onde os níveis de frutosamina mostraram comportamento semelhante aos de glicose nos períodos estudados, evidenciando deficiência de energia nos períodos de maior requerimento e maior risco para a ocorrência de distúrbios metabólicos.

A não ocorrência de variações nos valores médios da frutosamina ao longo dos momentos de observação, associados aos valores de albumina obtidos neste estudo reforçam a inexistência de balanço energético negativo nos animais estudados. Em função da ausência de valores fisiológicos deste metabólito na literatura, em ovelhas Santa Inês em final de gestação e durante a lactação, os valores obtidos tornam-se referência para futuros estudos.

$\mathrm{Na}$ avaliação dos triglicérides não houve diferença estatística entre os grupos de ovelhas estudadas e entre os momentos $(P>0,05)$, estando o valor médio obtido situado no intervalo de referência para a espécie ovina (Kaneko et al. 2008). Apesar de não haver diferença estatística entre 
Quadro 3. Valores médios e desvio padrão $(\mathrm{x} \pm \mathrm{s})$ das variáveis do perfil proteico no soro sanguíneo de ovelhas Santa Inês hígidas e com mastite subclínica acompanhadas no final da gestação e durante a lactação

\begin{tabular}{|c|c|c|c|c|c|c|c|}
\hline \multirow[t]{2}{*}{ Perfil proteico } & \multirow[t]{2}{*}{ Ovelhas } & \multicolumn{4}{|c|}{ Momentos de avaliação } & & \multirow[t]{2}{*}{$M G^{\mathrm{d}}$} \\
\hline & & 10 dap $^{a}$ & $15 \mathrm{dpp} \mathrm{p}^{\mathrm{b}}$ & $30 \mathrm{dpp}$ & 60dpp & 90dpp & \\
\hline \multirow{2}{*}{$\begin{array}{l}\text { Proteína total } \\
(\mathrm{g} / \mathrm{dL})\end{array}$} & Hígidas & $7,44 \pm 0,73$ & $7,12 \pm 0,95$ & $7,27 \pm 0,94$ & $7,54 \pm 0,68$ & $7,51 \pm 0,65$ & $7,38^{\mathrm{a}}$ \\
\hline & $\begin{array}{l}\text { Mast.Sub }{ }^{c} \text {. } \\
\text { MG }\end{array}$ & $\begin{array}{c}7,32 \pm 0,80 \\
7,38^{a}\end{array}$ & $\begin{array}{c}7,30 \pm 0,62 \\
7,21^{\text {a }}\end{array}$ & $\begin{array}{c}7,22 \pm 0,86 \\
7,25^{\mathrm{a}}\end{array}$ & $\begin{array}{c}7,53 \pm 0,50 \\
7,54^{\mathrm{a}}\end{array}$ & $\begin{array}{c}7,57 \pm 0,93 \\
7,54^{\mathrm{a}}\end{array}$ & $7,39^{\mathrm{a}}$ \\
\hline \multirow{2}{*}{$\begin{array}{l}\text { Albumina } \\
(\mathrm{g} / \mathrm{dL})\end{array}$} & Hígidas & $3,23 \pm 0,23$ & $2,89 \pm 0,26$ & $2,78 \pm 0,33$ & $2,67 \pm 0,26$ & $2,54 \pm 0,27$ & $2,82^{\mathrm{b}}$ \\
\hline & $\begin{array}{l}\text { Mast.Sub. } \\
\text { MG }\end{array}$ & $\begin{array}{c}3,14 \pm 0,34 \\
3,19^{\mathrm{a}}\end{array}$ & $\begin{array}{c}3,10 \pm 0,31 \\
3,00^{\mathrm{ab}}\end{array}$ & $\begin{array}{c}2,94 \pm 0,45 \\
2,87^{\mathrm{b}}\end{array}$ & $\begin{array}{c}2,82 \pm 0,37 \\
2,75^{\mathrm{b}}\end{array}$ & $\begin{array}{c}2,91 \pm 0,36 \\
2,73^{\mathrm{b}}\end{array}$ & $2,98^{\mathrm{a}}$ \\
\hline \multirow{2}{*}{$\begin{array}{l}\text { Uréia } \\
(\mathrm{mg} / \mathrm{dL})\end{array}$} & Hígidas & $39,17 \pm 10,99$ & $40,97 \pm 11,67$ & $35,63 \pm 12,38$ & $35,40 \pm 13,52$ & $44,17 \pm 16,44$ & $39,07^{a}$ \\
\hline & $\begin{array}{l}\text { Mast.Sub. } \\
\text { MG }\end{array}$ & $\begin{array}{c}49,72 \pm 8,80 \\
44,44^{a}\end{array}$ & $\begin{array}{c}46,38 \pm 20,54 \\
43,67^{a}\end{array}$ & $\begin{array}{c}41,50 \pm 14,54 \\
38,57^{a b}\end{array}$ & $\begin{array}{c}36,27 \pm 9,95 \\
35,84^{\mathrm{b}}\end{array}$ & $\begin{array}{c}40,43 \pm 12,15 \\
42,30^{\mathrm{ab}}\end{array}$ & $42,86^{\mathrm{a}}$ \\
\hline \multirow{2}{*}{$\begin{array}{l}\text { Creatinina } \\
(\mathrm{mg} / \mathrm{dL})\end{array}$} & Hígidas & $0,80 \pm 0,18$ & $0,72 \pm 0,09$ & $0,69 \pm 0,09$ & $0,73 \pm 0,13$ & $0,72 \pm 0,12$ & $0,73^{\mathrm{a}}$ \\
\hline & $\begin{array}{l}\text { Mast.Sub. } \\
\text { MG }\end{array}$ & $\begin{array}{c}0,79 \pm 0,18 \\
0,80^{\mathrm{a}}\end{array}$ & $\begin{array}{c}0,79 \pm 0,12 \\
0,76^{\mathrm{a}}\end{array}$ & $\begin{array}{c}0,74 \pm 0,12 \\
0,72^{\mathrm{a}}\end{array}$ & $\begin{array}{c}0,76 \pm 0,15 \\
0,74^{\mathrm{a}}\end{array}$ & $\begin{array}{c}0,74 \pm 0,12 \\
0,73^{\mathrm{a}}\end{array}$ & $0,76^{a}$ \\
\hline
\end{tabular}

os momentos, nota-se pequena elevação dos valores médios do período final de gestação ao final da lactação, variando de 17,58mg/dL a 21,51mg/dL (Quadro 2). Resultados semelhantes foram verificados por Karapehlivan et al. (2007), que relataram elevação dos valores desta variável ao longo da lactação de ovelhas da raça Tuj, embora mantivessem dentro da normalidade para ovinos. Por outro lado, Althaus et al. (1995), verificaram em ovelhas Corriedalle diminuição na concentração de triglicérides a partir dos 30 dias de lactação. Brito et al. (2006) não encontraram variações nos triglicérides em ovelhas leiteiras no Sul do Brasil, durante a gestação e a lactação.

As menores concentrações de triglicérides observadas no final da gestação e no início da lactação podem ser justificadas como resultante do aumento da produção de leite, da menor reserva de ácidos graxos livres disponíveis, da lipólise para obtenção de energia e do maior aporte de triglicérides circulantes para a glândula mamária, para síntese de gordura do leite (Mundim et al. 2007). Na análise do colesterol sérico verificou-se efeito de grupo $(\mathrm{P}<0,008)$ no qual as ovelhas portadoras de mastite subclínica apresentaram valores médios desta variável superiores às sadias durante a fase de lactação, muito embora se encontrassem situados no limite de normalidade para a espécie ovina (Kaneko et al. 2008). Foi observado efeito de momento $(\mathrm{P}<0,05)$ obtendo-se menores valores desta variável na fase inicial da lactação $(49,18 \mathrm{mg} / \mathrm{dL})$ e as maiores concentrações no período final $(57,69 \mathrm{mg} / \mathrm{dL}$ ) (Quadro 2). Na análise de regressão para a concentração de colesterol, o grupo das ovelhas com mastite apresentou efeito do tipo linear positivo $(\mathrm{P}<0,01)$.

$\mathrm{O}$ aumento gradual dos valores de colesterol durante a lactação de ovelhas da raça Lacaune foi também relatado por Brito et al. (2006), que verificaram concentrações deste metabólito superiores às observadas neste estudo, que segundo os autores não haveria justificativa para esta resposta. Comportamento semelhante desta variável, porém com concentrações mais elevadas, também foram relatados em ovelhas na Itália, durante a gestação e a lactação (Piccione et al. 2009). 0 aumento gradativo do colesterol durante a lactação estaria relacionado ao aumento da síntese de lipoproteínas no plasma (González \& Silva 2006, Pogliani et al. 2010). Outros autores verificaram aumento nos níveis de colesterol em vacas lactantes à medida que transcorreram as semanas pós-parto, correlacionando com a perda de peso e baixo escore corporal das vacas (Godoy et al. 2004) e com a necessidade de precursores para a síntese de hormônios esteroidais, os quais aumentam com o restabelecimento da atividade reprodutiva (Campos et al. 2007).

Perfil proteico. Na avaliação da concentração sérica da proteína total não foram observadas diferenças significativas entre os grupos $(\mathrm{P}>0,05)$ e entre os momentos de observação $(\mathrm{P}>0,05)$ (Quadro 3), estando os valores médios situados dentro da faixa de normalidade para espécie, conforme relatado por Kaneko et al. (2008) e Sucupira (2010). A discreta diminuição nos valores da proteína total nos primeiros trinta dias de lactação, mesmo que não significativo, coincide com a fase de maior produção de leite e paralelo a diminuição da concentração de albumina.

Comportamento semelhante aos observados neste estudo foi relatados por Krajničáková et al. (2003), em cabras leiteiras, por Piccione et al. (2009) em ovelhas leiteiras na Itália e por Soares et al. (2009) em ovelhas Dorper no Estado de Pernambuco. Por outro lado, Pinheiro \& Andrioli (2002) relataram situação mais crítica no período de estiagem no semi-árido nordestino, em que ovelhas sem raça definida (SRD) apresentaram no periparto valores desta variável abaixo da normalidade, sendo recomendada a suplementação proteica para as ovelhas gestantes e lactantes nesta época do ano.

Com relação às concentrações de albumina verificou-se diferença significativa entre os grupos, onde a maior média geral foi registrada no grupo de ovelhas com mastite subclínica, bem como diferença significativa entre os momentos (Quadro 1) observando-se maior valor médio no anteparto $(3,19 \mathrm{~g} / \mathrm{dL})$, quando comparado à lactação (Quadro 3). As equações de regressão para albumina apresentaram efeito do tipo linear negativo para ambos os grupos avaliados $(\mathrm{P}<0,05)$. A diminuição nos níveis de albumina durante a lactação está relacionada à maior demanda proteica para 
a síntese do leite (González et al. 2000). Valores decrescentes de albumina sérica em ovelhas no final da gestação e na lactação também foram relatados por Karapehlivan et al. (2007), Oliveira et al. (2008) e Cardoso et al. (2010). Os valores de albumina encontram-se situados dentro da normalidade considerada por Kaneko et al. (2008) e Sucupira (2010). Sendo a concentração de albumina um bom indicador de longos períodos de restrição proteica (Caldeira 2005), os resultados obtidos ratificam a não ocorrência de déficit proteico nos animais em estudo.

No que diz respeito à uréia, não houve diferença estatística $(\mathrm{P}>0,05)$ entre os grupos de ovelhas estudadas, contudo verificou-se diferença $(\mathrm{P}<0,05)$ entre os momentos de avaliação, onde o maior valor médio foi observado no momento ante parto $(44,44 \mathrm{mg} / \mathrm{dL})$ (Quadro 3). Resultados semelhantes foram reportados por Althaus et al. (1995), que observaram em ovelhas Corriedale lactantes valores decrescentes de uréia do início até o pico da lactação, com posterior recuperação no final da lactação.

Apesar do decréscimo na concentração de albumina e de uréia na fase de lactação, os resultados permitem afirmar não ter ocorrido nas ovelhas estudadas déficit proteico, pois os valores destas variáveis mantiveram-se dentro dos limites de normalidade para a espécie ovina (Contreras et al. 2000, Kaneko et al. 2008). A uréia responde mais rapidamente em relação à albumina a mudanças no aporte proteico da dieta para caracterização de deficiência proteica e sua concentração no soro sanguíneo reflete diretamente a quantidade de proteína ingerida (Contreras et al. 2000, González et al. 2000). A ocorrência de redução desses me- tabólitos proteicos com o avanço da gestação ou da lactação está associada ao balanço proteico negativo (Wittwer 2000, Ribeiro 2002). Relatos de aporte alimentar deficiente na lactação de ovelhas, resultantes de baixa concentração de uréia sérica foram relatadas por El-Sherif \& Assad (2001) e Cardoso et al. (2011).

Não foram observados efeito de grupo nem de momento $(P>0,05)$ para a variável creatinina (Quadro 3). Os valores médios de creatinina nas ovelhas Santa Inês foram semelhantes aos relatados por Santos et al. (2012) trabalhando com ovelhas da mesma raça no periparto e inferiores aos descritos por Kaneko et al. (2008).

Estes resultados ratificam o não comprometimento desta variável pela dieta, conforme relatado por Caldeira et al. (1999). Diferentemente deste estudo em ovelhas, Bertoni (1996) e Chiofalo et al. (2009) observaram em vacas e cabras leiteiras, respectivamente, elevação nos valores da creatinina nos momentos próximo ao parto, atribuindo este achado à mobilização de proteína muscular com o propósito de produzir energia no início da lactação.

\section{Perfil mineral}

Não foi verificada diferença estatística significativa nos valores de cálcio total entre os grupos de ovelhas, bem como durante os momentos de acompanhamento $(\mathrm{P}>0,05)$ (Quadro 4). Os valores de cálcio mantiveram-se dentro do limite de referência relatado por Contreras et al. (2000) em ovelhas no Chile, e inferiores aos reportados por Kaneko et al. (2008).

Apesar de não haver diferença estatística, nota-se que

Quadro 4. Valores médios e desvio padrão $(\mathrm{x} \pm \mathrm{s})$ das variáveis do perfil mineral e eletrolítico no soro sanguíneo de ovelhas Santa Inês hígidas e com mastite subclínica acompanhadas no final da gestação e durante a lactação

\begin{tabular}{|c|c|c|c|c|c|c|c|}
\hline \multirow{2}{*}{$\begin{array}{l}\text { Perfil mineral e } \\
\text { eletrolítico }\end{array}$} & \multirow[t]{2}{*}{ Ovelhas } & \multicolumn{4}{|c|}{ Momentos de avaliação } & & \multirow[t]{2}{*}{$\mathrm{MG}^{\mathrm{d}}$} \\
\hline & & 10dapa & $15 \mathrm{dpp}^{\mathrm{b}}$ & 30dpp & 60dpp & 90dpp & \\
\hline $\begin{array}{l}\text { Cálcio total } \\
\text { (mmol/L) }\end{array}$ & $\begin{array}{l}\text { Hígidas } \\
\text { Mast.Sub.c } \\
\text { MG }\end{array}$ & $\begin{array}{c}2,33 \pm 0,21 \\
2,24 \pm 0,23 \\
2,29^{a}\end{array}$ & $\begin{array}{c}2,20 \pm 0,16 \\
2,22 \pm 0,17 \\
2,21^{\mathrm{a}}\end{array}$ & $\begin{array}{c}2,19 \pm 0,20 \\
2,19 \pm 0,22 \\
2,19^{a}\end{array}$ & $\begin{array}{c}2,17 \pm 0,14 \\
2,27 \pm 0,27 \\
2,22^{\mathrm{a}}\end{array}$ & $\begin{array}{c}2,36 \pm 0,18 \\
2,26 \pm 0,26 \\
2,31^{a}\end{array}$ & $\begin{array}{l}2,25^{\mathrm{a}} \\
2,24^{\mathrm{a}}\end{array}$ \\
\hline $\begin{array}{l}\text { Cálcio ionizado } \\
\text { (mmol/L) }\end{array}$ & $\begin{array}{c}\text { Hígidas } \\
\text { Mast.Sub. } \\
\text { MG }\end{array}$ & $\begin{array}{c}0,86 \pm 0,12 \\
0,89 \pm 0,13 \\
0,88^{\mathrm{ab}}\end{array}$ & $\begin{array}{c}0,83 \pm 0,12 \\
0,76 \pm 0,11 \\
0,80^{\mathrm{b}}\end{array}$ & $\begin{array}{c}0,86 \pm 0,13 \\
0,86 \pm 0,13 \\
0,86^{b}\end{array}$ & $\begin{array}{c}0,76 \pm 0,19 \\
0,87 \pm 0,21 \\
0,82^{\mathrm{b}}\end{array}$ & $\begin{array}{c}1,04 \pm 0,14 \\
0,91 \pm 0,16 \\
0,98^{a}\end{array}$ & $\begin{array}{l}0,87^{\mathrm{a}} \\
0,86^{\mathrm{a}}\end{array}$ \\
\hline $\begin{array}{l}\text { Magnésio } \\
\text { (mg/dL) }\end{array}$ & $\begin{array}{c}\text { Hígidas } \\
\text { Mast.Sub. } \\
\text { MG }\end{array}$ & $\begin{array}{c}2,63 \pm 0,48 \\
2,66 \pm 0,44 \\
2,64^{a}\end{array}$ & $\begin{array}{c}2,47 \pm 0,54 \\
2,67 \pm 0,50 \\
2,57^{a}\end{array}$ & $\begin{array}{c}2,50 \pm 0,54 \\
2,37 \pm 0,39 \\
2,43^{\mathrm{a}}\end{array}$ & $\begin{array}{c}2,35 \pm 0,51 \\
2,47 \pm 0,48 \\
2,41^{a}\end{array}$ & $\begin{array}{c}2,25 \pm 0,33 \\
2,47 \pm 0,26 \\
2,36^{a}\end{array}$ & $\begin{array}{l}2,44^{\mathrm{a}} \\
2,53 \mathrm{a}\end{array}$ \\
\hline $\begin{array}{l}\text { Sódio } \\
\text { (mmol/L) }\end{array}$ & $\begin{array}{c}\text { Hígidas } \\
\text { Mast.Sub. } \\
\text { MG }\end{array}$ & $\begin{array}{c}143,42 \pm 3,00 \\
144,94 \pm 4,15 \\
144,18^{\mathrm{a}}\end{array}$ & $\begin{array}{c}141,80 \pm 2,97 \\
142,22 \pm 10,82 \\
142,01^{\mathrm{a}}\end{array}$ & $\begin{array}{c}143,42 \pm 5,48 \\
144,39 \pm 5,12 \\
143,90^{\mathrm{a}}\end{array}$ & $\begin{array}{c}143,67 \pm 3,28 \\
143,89 \pm 2,61 \\
143,78^{\mathrm{a}}\end{array}$ & $\begin{array}{c}142,11 \pm 3,79 \\
142,61 \pm 6,45 \\
142,36^{\mathrm{a}}\end{array}$ & $\begin{array}{l}142,88^{\mathrm{a}} \\
143,61^{\mathrm{a}}\end{array}$ \\
\hline $\begin{array}{l}\text { Potássio } \\
\text { (mmol/L) }\end{array}$ & $\begin{array}{c}\text { Hígidas } \\
\text { Mast.Sub. } \\
\text { MG }\end{array}$ & $\begin{array}{c}5,11 \pm 0,43 \\
5,04 \pm 0,45 \\
5,08^{a}\end{array}$ & $\begin{array}{c}5,10 \pm 0,49 \\
4,92 \pm 0,60 \\
5,01^{\mathrm{a}}\end{array}$ & $\begin{array}{c}5,18 \pm 0,42 \\
4,98 \pm 0,40 \\
5,08^{a}\end{array}$ & $\begin{array}{c}5,07 \pm 0,53 \\
5,12 \pm 0,50 \\
5,10^{\mathrm{a}}\end{array}$ & $\begin{array}{c}5,06 \pm 0,67 \\
5,09 \pm 0,41 \\
5,08^{a}\end{array}$ & $\begin{array}{l}5,10^{\mathrm{a}} \\
5,03^{\mathrm{a}}\end{array}$ \\
\hline $\begin{array}{l}\text { Ferro } \\
(\mathrm{mg} / \mathrm{L})\end{array}$ & $\begin{array}{c}\text { Hígidas } \\
\text { Mast.Sub. } \\
\text { MG }\end{array}$ & $\begin{array}{c}2,87 \pm 0,59 \\
2,69 \pm 0,74 \\
2,78^{a}\end{array}$ & $\begin{array}{c}3,18 \pm 0,61 \\
3,06 \pm 0,75 \\
3,12^{\mathrm{a}}\end{array}$ & $\begin{array}{c}3,25 \pm 1,24 \\
2,81 \pm 0,97 \\
3,03^{\mathrm{a}}\end{array}$ & $\begin{array}{c}3,10 \pm 0,73 \\
2,86 \pm 0,74 \\
2,98^{a}\end{array}$ & $\begin{array}{c}2,70 \pm 1,12 \\
2,82 \pm 0,72 \\
2,76^{a}\end{array}$ & $\begin{array}{l}3,02^{\mathrm{a}} \\
2,85^{\mathrm{a}}\end{array}$ \\
\hline $\begin{array}{l}\text { Zinco } \\
\text { (mg/L) }\end{array}$ & $\begin{array}{l}\text { Hígidas } \\
\text { Mast.Sub. } \\
\text { MG }\end{array}$ & $\begin{array}{c}0,56 \pm 0,07 \\
0,56 \pm 0,14 \\
0,56^{a}\end{array}$ & $\begin{array}{c}0,54 \pm 0,12 \\
0,58 \pm 0,19 \\
0,56^{a}\end{array}$ & $\begin{array}{c}0,56 \pm 0,20 \\
0,62 \pm 0,17 \\
0,59^{\mathrm{a}}\end{array}$ & $\begin{array}{c}0,55 \pm 0,13 \\
0,58 \pm 0,15 \\
0,57^{a}\end{array}$ & $\begin{array}{c}0,56 \pm 0,25 \\
0,61 \pm 0,17 \\
0,59^{a}\end{array}$ & $\begin{array}{l}0,55^{\mathrm{a}} \\
0,59^{\mathrm{a}}\end{array}$ \\
\hline $\begin{array}{l}\text { Cobre } \\
\text { (mg/L) }\end{array}$ & $\begin{array}{l}\text { Hígidas } \\
\text { Mast.Sub. } \\
\text { MG }\end{array}$ & $\begin{array}{c}1,08 \pm 0,35 \\
1,12 \pm 0,30 \\
1,10^{\mathrm{a}}\end{array}$ & $\begin{array}{c}0,97 \pm 0,42 \\
1,12 \pm 0,30 \\
1,05^{a}\end{array}$ & $\begin{array}{c}0,98 \pm 0,39 \\
1,25 \pm 0,40 \\
1,12^{\mathrm{a}}\end{array}$ & $\begin{array}{c}1,04 \pm 0,36 \\
1,18 \pm 0,38 \\
1,11^{\mathrm{a}}\end{array}$ & $\begin{array}{c}1,16 \pm 0,37 \\
1,17 \pm 0,44 \\
1,17^{a}\end{array}$ & $\begin{array}{l}1,05^{\mathrm{b}} \\
1,17^{\mathrm{a}}\end{array}$ \\
\hline
\end{tabular}

${ }^{\mathrm{a}} \mathrm{dap}=$ dias antes do parto, ${ }^{\mathrm{b}} \mathrm{dpp}=$ dias pós parto, ${ }^{\mathrm{c}}$ Mast. Sub. $=$ Mastite subclínica, ${ }^{\mathrm{d}} \mathrm{MG}=$ Média Geral . 
os valores apresentaram discreto declínio nos primeiros 60 dias da lactação, fase em que ocorre maior demanda de cálcio para a síntese do leite (Althaus et al. 1995). Na avaliação da concentração sérica de cálcio ionizado não foi verificada diferença entre os grupos, no entanto houve diferença entre os momentos (Quadro 1), particularmente no início da lactação (15dpp), momento em que se observa o decréscimo nos valores desta variável, apresentando os menores valores da lactação $(0,80 \mathrm{mmol} / \mathrm{L})$, quando comparado a fase de secagem aos 90 dias (0,98mmol/L) (Quadro 4). Este decréscimo nesta fase da lactação é ratificado pelo efeito quadrático desta variável ao longo dos momentos de observação, verificado em ambos os grupos estudados $(\mathrm{P}<0,05)$.

Os valores médios do cálcio ionizado seguiram a mesma dinâmica observada para as concentrações do cálcio total, onde foi observada diminuição nos níveis destes no início da lactação e discreta elevação com o avanço da lactação, sendo na forma ionizada verificado o efeito estatístico $(\mathrm{P}<0,05)$. Este decréscimo do cálcio na corrente sanguínea nesta fase da lactação está diretamente relacionado à síntese de colostro e leite, sendo este o principal mineral na composição de ambos (Althaus et al. 1995). Valores médios superiores, de cálcio ionizado, aos observados neste estudo foram relatados por Mundim et al. (2007) em cabras leiteiras.

$\mathrm{Na}$ avaliação dos níveis de magnésio sérico, verificou-se não haver diferença significativa $(\mathrm{P}>0,05)$ entre os grupos e entre os momentos de observação $(\mathrm{P}>0,05)$ (Quadro 4). Os valores obtidos estão situados dentro dos valores de normalidade descritos por González et al. (2000) e Kaneko et al. (2008). Valores médios semelhantes aos obtidos neste estudo foram relatados por Dias et al. (2010) em ovelhas Churra-de Terra-Quente e por Cardoso et al. (2011) em ovelhas Santa Inês no estado do Pará durante os diferentes estágios da lactação.

As concentrações de sódio e potássio (Quadro 4) não apresentaram diferença estatística entre os grupos $(\mathrm{P}>0,05)$ e entre os diferentes momentos $(\mathrm{p}>0,05)$ de acompanhamento das ovelhas. Os valores encontrados para sódio e potássio situaram-se no intervalo de normalidade para a espécie (Kaneko et al. 2008). Resultados semelhantes foram relatados por Althaus et al. (1995) em ovelhas Corriedale e por Dias et al. (2010), em ovelhas Churra-de-Terra-Quente em Portugal. Por outro lado, Yildiz et al. (2005) relatou a diminuição nos teores de sódio e potássio próximo ao parto e nos primeiros dias da lactação, atribuindo este achado como resultado da mobilização desses íons para formação do colostro, variação esta não visualizada neste estudo.

Com relação às concentrações séricas do ferro e do zinco (Quadro 4) não foi encontrada diferença estatística significativa entre os grupos $(P>0,05)$ e entre os momentos de observação $(\mathrm{P}>0,05)$. Todavia foram constatados valores médios inferiores do ferro sérico nas ovelhas com mastite subclínica; esta discreta redução pode estar relacionada ao quadro subclínico da enfermidade, em virtude desta alteração ser mais expressiva nos casos clínicos de mastite, conforme relatado por Costa et al. (2010) trabalhando com ovelhas Santa Inês infectadas experimentalmente com Staphylococcus aureus, onde relataram o declínio do ferro após $24 \mathrm{~h}$ da infecção. Achados semelhantes aos deste estu- do foram relatados por Burriel \& Heys (1997) em ovelhas com infecção intramamária causada por Staphylococcus coagulase negativo e em vacas com mastite subclínica (Yildiz \& Kaygusuzoğlu 2005). A redução dos teores de ferro sanguíneo em resposta a processos inflamatórios está relacionada ao mecanismo de defesa inespecífico do hospedeiro contra as infecções bacterianas, indisponibilizando estes elementos aos micro-organismos (Sandholm 1995).

Com relação aos teores de zinco, estes mantiveram-se constantes durante todos os momentos de observação, diferentemente do relatado por Elnageeb \& Adelatif (2010), que verificaram elevação significativa desta variável próximo ao parto e decréscimo gradual com o avanço da lactação das ovelhas. Resultados semelhantes foram descritos por Yildiz \& Kaygusuzoğlu (2005), que não observaram diferença significativa nos teores de zinco entre vacas sadias e com mastite subclínica.

As concentrações séricas de cobre apresentaram diferença significativa entre os grupos $(\mathrm{P}<0,05)$, onde a maior média geral foi registrada no grupo de ovelhas com mastite subclínica (1,17mg/L) (Quadro 4). Não foi observada diferença $(\mathrm{P}>0,05)$ entre os momentos, não havendo influência deste período estudado sobre os teores de cobre sérico, diferente do relatado por Elnageeb \& Adelatif (2010), em ovelhas no parto e durante a lactação. Os maiores valores médios observados nas ovelhas com mastite subclínica em todos os momentos de avaliação, pode ser explicado pela relação deste mineral com a ceruloplasmina, uma proteína de fase aguda presente no soro sanguíneo, que transporta cerca de $90 \%$ do cobre presente no plasma e está elevada nos processos inflamatórios da glândula mamária (Costa et al. 2010). Resultados semelhantes, nos quais os níveis de cobre se elevaram com a infecção, foram reportados por Lamand \& Levieux (1981), em ovelhas com mastite subclínica e Yildiz \& Kaygusuzoğlu (2005), que observaram valores superiores deste elemento em vacas com mastite subclínica, quando comparadas às vacas sadias.

\section{Soro lácteo}

As fontes de variação, o valor de F da análise de variância e o nível de $P$ das variáveis referentes aos metabólitos avaliados no soro lácteo de glândulas sadias e com mastite subclínica podem ser visualizados no Quadro 5.

Diferença significativa na concentração de sódio no

Quadro 5. Nível de significância (Pr>F) dos fatores de variação (grupos, momentos e interações) da análise de variância das variáveis do soro lácteo de glândulas mamárias sadias e com mastite subclínica de ovelhas Santa Inês acompanhadas durante a lactação

\begin{tabular}{llcc}
\hline \multirow{2}{*}{ Variáveis } & \multicolumn{3}{c}{ Fatores de variação (Pr > F) } \\
\cline { 2 - 4 } & Grupos & Momentos & G x M \\
\cline { 2 - 4 } & 0,0198 & 0,3729 & 0,4509 \\
\hline Sódio (mmol/L) & 0,0003 & 0,0173 & 0,9082 \\
Potássio (mmol/L) & 0,4309 & 0,4014 & 0,2735 \\
Cálcio ionizado (mmol/L) & 0,4370 & 0,1723 & 0,9667 \\
ß-hidroxibutirato (mmol/L) & $<, 0001$ & 0,2760 & 0,3459 \\
AGNEs $^{\text {a }}$ (mmol/L) & & &
\end{tabular}

${ }^{\mathrm{a}}$ AGNEs = Ácidos graxos não esterificados. 


\section{Quadro 6. Valores médios e desvio padrão $(\mathrm{x} \pm \mathrm{s})$ das variáveis no soro lácteo de glândulas mamárias sadias e com mastite subclínica de ovelhas Santa Inês durante a lactação}

\begin{tabular}{lccccc}
\hline \multicolumn{1}{c}{ Variáveis } & Glândulas & \multicolumn{3}{c}{ Momentos de avaliação } & MG $^{\mathrm{d}}$ \\
\cline { 3 - 5 } & mamárias & $15 \mathrm{dpp}^{\mathrm{b}}$ & $30 \mathrm{dpp}$ & $60 \mathrm{dpp}$ & 90dpp \\
\hline Sódio & Sadias & $173,18 \pm 13,82$ & $182,18 \pm 51,53$ & $207,67 \pm 63,76$ & $182,83^{\mathrm{b}}$ \\
(mmol/L) & Mast. Sub & $226,25 \pm 86,15$ & $194,50 \pm 32,94$ & $213,38 \pm 38,10$ & $208,26^{\mathrm{a}}$ \\
& MG & $199,72^{\mathrm{a}}$ & $188,34^{\mathrm{a}}$ & $210,53^{\mathrm{a}}$ & \\
Potássio & Sadias & $35,10 \pm 0,62$ & $33,65 \pm 0,57$ & $32,53 \pm 0,83$ & $34,58^{\mathrm{a}}$ \\
(mmol/L) & Mast. Sub. & $29,34 \pm 1,40$ & $26,48 \pm 1,55$ & $26,03 \pm 2,52$ & $28,66^{\mathrm{b}}$ \\
& MG & $32,22^{\mathrm{ab}}$ & $30,07^{\mathrm{ab}}$ & $29,28^{\mathrm{b}}$ & \\
Cálcio ionizado & Sadias & $4,12 \pm 0,62$ & $4,29 \pm 0,57$ & $5,13 \pm 0,83$ & $4,53^{\mathrm{a}}$ \\
(mmol/L) & Mast. Sub. & $4,04 \pm 1,40$ & $4,19 \pm 1,55$ & $3,99 \pm 2,52$ & $4,19^{\mathrm{a}}$ \\
& MG & $4,08^{\mathrm{a}}$ & $4,24^{\mathrm{a}}$ & $4,56^{\mathrm{a}}$ & \\
ß-hidroxibutirato & Sadias & $0,03 \pm 0,01$ & $0,03 \pm 0,02$ & $0,02 \pm 0,02$ & $0,03^{\mathrm{a}}$ \\
(mmol/L) & Mast. Sub. & $0,03 \pm 0,02$ & $0,02 \pm 0,01$ & $0,02 \pm 0,01$ & $0,02^{\mathrm{a}}$ \\
& MG & $0,03^{\mathrm{a}}$ & $0,03^{\mathrm{a}}$ & $0,02^{\mathrm{a}}$ & \\
AGNEs & Sadias & $0,03 \pm 0,02$ & $0,03 \pm 0,03$ & $0,01 \pm 0,01$ & $0,03^{\mathrm{b}}$ \\
(mmol/L) & Mast. Sub. & $0,15 \pm 0,15$ & $0,08 \pm 0,08$ & $0,08 \pm 0,08$ & $0,12^{\mathrm{a}}$ \\
& MG & $0,11^{\mathrm{a}}$ & $0,09^{\mathrm{a}}$ & $0,05^{\mathrm{a}}$ & $0,05^{\mathrm{a}}$
\end{tabular}

${ }^{\mathrm{a}}$ AGNEs = Ácidos graxos não esterificados, ${ }^{\mathrm{b}} \mathrm{dpp}=$ dias pós parto, ${ }^{\mathrm{c}}$ Mast. Sub. = Mastite subclínica, ${ }^{\mathrm{d}} \mathrm{MG}=$ Média Geral.

soro lácteo foi observada entre glândulas sadias e com mastite subclínica (Quadro 5), verificando valores médios mais elevados nas glândulas infectadas $(208,26 \mathrm{mmol} / \mathrm{L})$ (Quadro 6). Ao longo dos momentos de observação a concentração de sódio no soro lácteo não apresentou variações significativas entre os momentos $(\mathrm{P}>0,05)$, no entanto, vale ressaltar que entre as médias obtidas para cada momento ao longo da lactação, os valores foram sempre superiores para as glândulas com mastite subclínica.

Houve diferença significativa nas concentrações médias de potássio no soro lácteo entre os dois grupos (Quadro 5). A maior média obtida foi observada nas glândulas sadias (34,58 mmol/L) (Quadro 6). Também foram observadas diferenças significativas nas concentrações médias de potássio entre os momentos (Quadro 6), em que os valores médios decresceram ao longo da lactação, observando maior média aos $15 \mathrm{dpp}(34,92 \mathrm{mmol} / \mathrm{L})$ e a menor média aos $90 \mathrm{dpp}(29,28 \mathrm{mmol} / \mathrm{L})$. Apesar da ocorrência de variação entre os momentos observou-se dinâmica de regressão do tipo linear negativo em ambos os grupos $(\mathrm{p}<0,05)$ ao longo da lactação.

El Zubeir et al. (2005) encontraram níveis mais elevados de sódio no leite de vacas com mastite e redução nos teores de potássio, em relação aos valores obtidos no leite das vacas sadias. Do mesmo modo, Shitandi et al. (2005) e Batavani et al. (2007) observaram elevação nos níveis de sódio e diminuição nos teores de potássio no leite de vacas com mastite subclínica. Tais alterações foram mais evidentes quanto maiores a contagem de células somáticas, ou seja, a intensidade da reação inflamatória. A infecção da glândula mamária resulta em danos ao epitélio ductal e secretor, causando aumento da permeabilidade dos capilares sanguíneos. Desta forma o sódio (que é mais concentrado no fluído extracelular) passa para o lúmen dos alvéolos a fim de manter a osmolaridade, consequentemente os níveis de potássio diminuem. As alterações observadas nos níveis de sódio e potássio no soro lácteo estão relacionadas com a redução de atividade das células secretoras e aumento da permeabilidade do epitélio mamário. Estes achados confirmam que alterações observadas nos níveis destes íons no soro lácteo constituem bom indicador de infecção da glândula mamária na ovelha, sendo este um parâmetro já utilizado para vacas (El Zubeir et al. 2005).

Com relação às concentrações de cálcio ionizado no soro lácteo, não foram observadas diferença significativa entre as glândulas sadias e infectadas $(P>0,05)$ e entre os momentos de observação $(P>0,05)$ (Quadro 6). Apesar de não ter sido constatada diferença significativa entre os grupos, vale salientar que os valores médios, observados em toda a lactação, foram inferiores nas glândulas mamárias com mastite subclínica, podendo ser reflexo do efeito da infecção sobre a concentração do cálcio (Korhonen \& Kaartinen 1995). Este tipo de alteração foi relatada por Yildiz \& Kaygusuzoğlu (2005), Shitandi et al. (2005) e Batavani et al. (2007) em vacas com mastite, quando comparado ao leite de vacas sadias.

Avaliando a composição do leite de cabras com mastite subclínica, Leitner et al. (2004), observaram resultados semelhantes aos observados para as ovelhas com mastite subclínica neste estudo, em que as concentrações de cálcio não diferiram entre os grupos, porém a sua concentração foi inferior no leite das cabras infectadas.

Apesar de não significativo, os valores inferiores de cálcio ionizado no soro lácteo das ovelhas com mastite, pode estar relacionado aos danos deletérios provocados por patógenos no epitélio secretor que é essencialmente impermeável ao transporte do cálcio a partir do leite para o sangue (El Zubeir et al. 2005).

Os valores médios obtidos para BHB no soro lácteo não apresentaram diferença significativa entre as glândulas e entre os momentos $(\mathrm{P}>0,05)$. As concentrações de BHB no soro lácteo foram bem inferiores àquelas observadas no soro sanguíneo (Quadro 6). Na glândula mamária este metabólito é empregado na síntese de ácidos graxos (Corrêa 
et al. 2010). González \& Campos (2003) relataram valores bem superiores de BHB no leite de vacas, quando comparado aos encontrados neste estudo. Dois fatores poderiam estar relacionados a esta diferença, a espécie animal e o fato de ter sido utilizado o soro lácteo.

As concentrações médias de ácidos graxos não esterificados (AGNEs) no soro lácteo apresentaram diferenças significativas entre as glândulas sadias e infectadas (Quadro 5), observando valores médios superiores nas glândulas com mastite subclínica $(0,12 \mathrm{mmol} / \mathrm{L}$ ) (Quadro 6). Este grupo apresentou em todos os momentos concentrações médias mais elevadas, principalmente no início da lactação. Esta alteração estaria relacionada à elevação da atividade lipolítica presente no leite mastítico por aumento da ação enzimática (lipase) (Korhonen \& Kaartinen 1995).

Não foi observado efeito de momento $(\mathrm{P}>0,05)$ sobre os valores desta variável, no entanto verificarams-se maiores concentrações no primeiro mês da lactação em ambos os grupos e em maior intensidade no soro lácteo das glândulas infectadas. Na análise de regressão para as concentrações de AGNEs, verificou-se tendência de regressão do tipo linear negativo $(\mathrm{P}<0,07)$, para as glândulas com mastite subclínica.

Semelhantemente ao observado com o BHB neste estudo, os valores médios encontrados para as concentrações de AGNEs no soro lácteo são bem inferiores àqueles observados no sangue $(0,07 \mathrm{mmol} / \mathrm{L}$ e $0,59 \mathrm{mmol} / \mathrm{L}$, respectivamente).

Vale ressaltar a inexistência na literatura de valores médios de BHB e AGNEs no soro lácteo de ovelhas durante a lactação, em condição fisiológica e com mastite subclínica, podendo estes resultados serem úteis em futuros trabalhos.

\section{CONCLUSÃO}

0 maior requerimento energético, protéico e mineral ocorreu no primeiro mês da lactação sem, entretanto, desencadear qualquer transtorno metabólico, apesar da lipomobilização de baixa magnitude, sendo estas discretas alterações mais expressivas nas ovelhas com mastite subclínica.

Agradecimentos.- À Coordenação de Aperfeiçoamento de Ensino Superior (CAPES) pela concessão da Bolsa de Demanda Social.

\section{REFERÊNCIAS}

Afonso J.A.B. 2005. Doenças carenciais e metabólicas e sua influência na exploração de caprinos e ovinos. Anais do Seminário Norte-Rio Grandense de Caprinocultura e Ovinocultura, Mossoró, CE.

Althaus R.L., Roldán V., Scaglione L., Elizalde E., Jorge S. \& Malinskas G. 1995. Perfiles metabólicos en ovejas lactantes Corriedale: variación durante la lactancia. Revta Argent. Prod. Anim. 15:1055-1058.

Batavani R.A., Asri S. \& Naebzadeh H. 2007. The effect of subclinical mastitis on milk composition in dairy cows. Iranian J. Vet. Res. 8(3):205-211.

Bertoni G. 1996. Feeding and bovine milk quality: endocrine and metabolic factors. Zootec. Nutr. Anim. 22:205-214.

Brito A.M., González F.D., Ribeiro L.A., Campos R., Barbosa P.R. \& Bergman G. 2006. Composição do sangue e do leite em ovinos leiteiros do sul do Brasil: variações na gestação e lactação. Ciência Rural 36(3):1-7.

Burriel A.R. \& Heys V. 1997. Serum and milk iron levels during sheep intramammary infection caused by coagulase-negative staphylococci. Biol. Trace Element Res. 59(1/3):153-158.
Caldeira R.M. 2005. Monitoração da adequação do plano alimentar e do estado nutricional em ovelhas. Revta Port. Ciênc. Vet. 100(555/556):125139.

Caldeira R.M., Almeida M.A. \& Santos C.C. 1999. Daily variation in blood enzymes and metabolites in ewes under three levels of feed intake. Can. J. Anim. Sci. 79:157-164.

Caldeira R.M., Belo A.T., Santos C.C., Vazques M.I. \& Portugal A.V. 2007. The effect of body condition score on blood metabolites and hormonal profiles in ewes. Small Rumin. Res. 68:233-241.

Campos R., González F., Coldebella A. \& Lacerda L. 2007. Indicadores do metabolismo energético no pós-parto de vacas leiteiras de alta produção e sua relação com a composição do leite. Ciênc. Anim. Bras. $8(2): 241-249$.

Cardoso E.C., Oliveira D.R., Balaro M.F.A., Rodrigues L.F.S. \& Brandão F.Z. 2011. Índices produtivos e perfil metabólico de ovelhas Santa Inês no pós-parto no nordeste do Pará. Revta Bras. Ciênc. Vet. 18(2/3):114-120.

Cardoso E.C., Oliveira D.R., Dourado A.P., Araújo C.V., Ortolani E.L. \& Brandão F.Z. 2010. Peso e condição corporal, contagem de OPG e perfil metabólico sanguíneo de ovelhas da raça Santa Inês no periparto, criadas na região da Baixada Litorânea do Estado do Rio de Janeiro. Revta Bras. Ciênc. Vet. 17(2):77-82.

Chiofalo V., D'Aquino S., Scinardo Tenghi E., Sanzarello L., Chiofalo B., Piccitto F., Cavallaro M. \& Liotta L. 2009. Efect of peripartal propylene glycol suplementation on some biochemical parameters in dairy goats. Tropical and Subtropical Agroecosystems 11(1):215-217.

Contreras P.A., Wittwer F. \& Böhmwald H. 2000. Uso dos perfis metabólicos no monitoramento nutricional dos ovinos, p.75-88. In: González F.H.D., Barcelos J.O., Ospina H. \& Ribeiro L.A.O. (Eds), Perfil Metabólico em Ruminantes: seu uso em nutrição e doenças nutricionais. Universidade Federal do Rio Grande do Sul, Porto Alegre.

Corrêa M.N., González F.H.D. \& Silva S.C. 2010. Transtornos Metabólicos nos Animais Domésticos. Editora e Gráfica Universitária, Pelotas. 520p.

Costa N.A., Simão L.C.V., Santos R.A., Afonso J.A.B., Fagliari J.J., Cardoso E.C., Soares P.C. \& Mendonça C.L. 2010. Proteinograma e teores de cobre, ferro e zinco no soro sanguíneo de ovelhas da raça Santa Inês com mastite experimental por Staphylococcus aureus. Pesq. Vet. Bras. 30(5):435-442.

Dias I.R., Viegas C.A., Silva A.M., Pereira H.F., Sousa C.P., Carvalho P.P., Cabrita A.S., Fontes P.J., Silva S.R. \& Azevedo J.M.T. 2010. Haematological and biochemical parameters in Churra-da-Terra-Quente ewes from the northeast of Portugal. Arq. Bras. Med. Vet. Zootec. 62(2):265-272.

Diffay B.C., Mckenzie D., Wolf C. \& Pugh D.G. 2005. Abordagem e exame de ovinos e caprinos, p.1-19. In: Pugh D.G. (Ed.), Clínica de Ovinos e Caprinos. Roca, São Paulo.

El Zubeir I.E.M., Elowni O.A.O. \& Mohamed G.E. 2005. Effect of mastitis on macro-minerals of bovine milk and blood serum in Sudan. J. South African Vet. Assoc. 76(1):22-25.

Elnageeb M.E. \& Adelatif A.M. 2010. The minerals profile in desert ewes (Ovis aries): Effects of pregnancy, lactation and dietary supplementation. Am.-Eurasian J. Agricult. Environ. Sci. 7(1):18-30.

El-Sherif M.M.A. \& Assad F. 2001. Changes in some blood constituints of Bark ewes during pregnancy and lactation under semi arid conditions. Small Rumin. Res. 40:269-277.

Filipovi'c N., Stojevi'c Z., Masek T., Mikulec Z. \& Prvanovi'c N. 2011. Relationship between fructosamine with serum protein, albumin and glucose concentrations in dairy ewes. Small Rumin. Res. 96:46-48.

Godoy M.M., Alves J.B. \& Monteiro A.L.G. 2004. Parâmetros reprodutivo e metabólico de vacas da raça Guzerá suplementadas no pré e pós-parto. Revta Soc. Bras. Zootec. 33(1):103-111.

González F.H.D. \& Campos R. 2003. O leite como indicador metabólico-nutricional em vacas. Hora Vet. 22:36-38.

González F.H.D. \& Silva S.C. 2006. Introdução à Bioquímica Clínica Veterinária. $2^{\underline{a}}$ ed. Universidade Federal do Rio Grande do Sul, Porto Alegre. $358 \mathrm{p}$.

González F.H.D., Barcellos J.O., Patiño H.O. \& Ribeiro L.A.O. 2000. Perfil Metabólico em Ruminantes: Seu Uso em Nutrição e Doenças Nutricionais. 
Gráfica da Universidade Federal do Rio Grande do Sul, Porto Alegre. 108 p.

Kaneko J.J., Harvey J.W. \& Bruss M.L. 2008. Clinical Biochemestry of Domestic Animals. $6^{\text {th }}$ ed. Academic Press, San Diego. 916p.

Karapehlivan M., Atakisi E., Atakisi O., Yucayurt R. \& Pancarci S.M. 2007. Blood biochemical parameters during the lactation and dry period in Tuj ewes. Small Rumin. Res. 73:267-271.

Korhonen H. \& Kaartinen L. 1995. Changes in the composition of milk induced by mastitis, p.76-82. In: Sandholml M., Buzalski T.H., Kaartinen L. \& Pyorala S. (Eds), The Bovine Udder and Mastitis. Gummerus Kirjapaino, Helsinki.

Krajničáková M., Kováč V., Kostecký M., Valocký I., Maraček I., Sutiaková I. \& Lenhardt L. 2003. Selected clinic-biochemical parameters in the puerperal period of goats. Bull. Vet. Inst. Pulawy 47:177-182.

Lamand M. \& Levieux D. 1981. Effects of infection on plasma levels of copper and zinc in ewes. Annales de Recherches Vétérinaires 12(2):133136.

Leitner G., Merin U. \& Silanikove N. 2004. Changes in milk composition as affected by subclinical mastitis in goats. J. Dairy Sci. 87:1719-1726.

Lemos V.F. 2011. Proteinograma do soro sanguíneo e lácteo de ovelhas da raça Santa Inês em diferentes fases da lactação. Dissertação de Mestrado em Sanidade e Reprodução de Ruminantes, Unidade Acadêmica de Garanhuns, Universidade Federal Rural de Pernambuco, Garanhuns, PE. 99p.

Mallard B.A., Dekkers J.C., Ireland M.J., Leslie K.E., Sharif S., Lacey Vankampen C., Wagter L. \& Wilkie B.N. 1998. Alteration in immune responsiveness during the peripartum period and its ramification on dairy cow and calf health. J. Dairy Sci. 81(2):585-595.

Moyes K.M., Larsen T., Friggens N.C., Drackley J.K. \& Ingvartsen K.L. 2009. Identification of potential markers in blood for the development of subclinical and clinical mastitis in dairy cattle at parturition and during early lactation. J. Dairy Sci. 92(11):5419-5428.

Mundim A.V., Costa A.S., Mundim S.A.P., Guimarães E.C. \& Espindola F.S. 2007. Influência da ordem e estágio da lactação no perfil bioquímico sanguíneo de cabras da raça Saanen. Arq. Bras. Med. Vet. Zootec. 59:306312.

National Mastitis Council 1990. Microbiological Procedures for the Diagnosis of Bovine Udder Infection. $3^{\text {rd }}$ ed. NMC, Arlington. 34p.

Oliveira D.R., Cardoso E.C., Dourado A.P., Brandão F.Z., Ortolani E.L., Minervino A.H.H., Araújo C.V. \& Oliveira J.S.K. 2008. Perfil metabólico de ovelhas da raça Santa Inês durante o período periparto na baixada litorânea do Estado do Rio de Janeiro: proteína, energia e minerais. Anais do 35ํㅜ Conbravet, Gramado, RS.

Piccione G., Caola G., Giannetto C., Grasso F., Runzo S.C., Zumbo A. \& Pennisi P. 2009. Selected biochemical serum parameters in ewes during pregnancy, post-parturition, lactation and dry period. Anim. Sci. Pap. Rep. 27(4):321-330.

Pinheiro R.R. \& Andrioli A. 2002. Constituintes bioquímico-séricos em ovinos sem raça definida (SRD) no semi-árido nordestino. Revta Bras. Med. Vet. 24(2):65-66.

Pogliani F.C., Azedo M.R., Souza R.M., Raimondo R.F.S. \& Birgel Júnior E.H. 2010. Influência da gestação e do puerpério no lipidograma de bovinos da raça holandesa. Arq. Bras. Med. Vet. Zootec. 62(2):273-280.
Quinn P.J., Carter M.E., Markeu B. \& Carter G.R. 1994. Clinical Veterinary Microbiology. Mosby, Philadelphia. 648p.

Ribeiro L.A.O. 2002. Perdas reprodutivas em ovinos no Rio Grande do Sul determinadas pelas condições nutricionais e de manejo no encarneiramento e na gestação. Tese de Doutorado em Ciências Veterinárias, Universidade Federal do Rio Grande do Sul, Porto Alegre, RS. 106p.

Ribeiro L.A.O., Mattos R.C., González F.H.D., Wald V.B., Silva M.A. \& La Rosa V.L. 2004. Perfil metabólico de ovelhas Border Leicester x Texel durante a gestação e a lactação. Revta Port. Ciênc. Vet. 99(551):155-159.

Rios C., Marín M.P., Catafau M. \& Wittwer F. 2006. Concentraciones sanguíneas de $\beta$-hidroxibutirato, NEFA, colesterol e urea em cabras lecheras de três rebaños com sistemas intensivos de producción y su relación com el balance nutricional. Archs Med. Vet. 38(1):19-23.

Sampaio I.B.M. 2007. Estatística Aplicada à Experimentação Animal. 3aㅡ ed. FEP-MVZ Editora, Belo Horizonte. 265p.

Sandholm M. 1995. Inflammation in mastitis, p.59-75. In: Sandholml M., Buzalski T.H., Kaartinen L. \& Pyorala S. (Eds), The Bovine Udder and Mastitis. Gummerus Kirjapaino, Helsinki.

Santos R.A., Campos A.G.S.S., Afonso J.A.B., Soares P.C. \& Mendonça C.L. 2012. Efeito da administração de propileno glicol e cobalto associado à vitamina B12 sobre o perfil metabólico e a atividade enzimática de ovelhas da raça Santa Inês no periparto. Pesq. Vet. Bras. 32(Supl.1):60-66.

Schalm O.W., Carroll E.J. \& Jain N.C. 1971. Bovine Mastitis. Lea and Febiger, Philadelphia. 360p.

Shitandi A., Ogollah H. \& Nanua J.N. 2005. Effect of subclinical mastitis on milk composition in the Kenyan smallholder dairy herds. African Crop Sci. Conf. Proc. 7:545-550.

Smith M.C. \& Sherman D.M. 2009. Goat Medicine. $2^{\text {nd }}$ ed. Lea and Febiger, Philadelphia. 871p.

Soares F.A.P., Neto A.V.B., Guimarães J.A., Dantas A.C., Carvalho C.C.D. \& Marques A.V.C. 2009. Metabolismo de indicadores preditivos da toxemia da prenhez em ovelhas Dorper no terço final da gestação, parto e pós-parto. Anais VIII Congresso Brasileiro de Buiatria. Ciênc. Anim. Bras. 1(Supl.):197-203.

Solamain S.G., Maloney M.A., Quershi M.A., Davis G. \& Dandrea G. 2001. Effects of high copper supplements on performance health, plasma copper and enzymes in goats. Small Rumin. Res. 41(2):127-139.

Statistical Analyses System Institute. 2009. SAS User's Guide: statistics version. Cary, New York. 305p.

Sucupira M.C.A. 2010. Perfil metabólico no período periparto. 5ํㅡㄹesso Internacional Finco, São Paulo. (Comunicação oral)

Wittwer F. 2000. Marcadores bioquímicos no controle de problemas metabólicos nutricionais em gado de leite, p.56-62. In: González F.H.D., Barcellos J.0., Patiño H.O. \& Ribeiro L.A.O. (Eds), Perfil Metabólico em Ruminantes: seu uso em nutrição e doenças nutricionais. Gráfica da Universidade Federal do Rio Grande do Sul, Porto Alegre.

Yildiz A., Balikci E. \& Gurdogan F. 2005. Serum mineral levels at pregnancy and postpartum in single and twin pregnant sheep. Biol. Trace Element Res. 107:247-254.

Yildiz H. \& Kaygusuzoğlu E. 2005. Investigation of Ca, Zn, Mg, Fe and Cu concentrations in blood and milk of cows with negative and positive CMT results. Bull. Vet. Inst. Pulawi 49:209-213. 